\title{
Sleeping Behavior and Its Importance in Albanian Children and Teenagers Living in Tirana
}

\author{
Saimir Shatku \\ Faculty of Physical Activity and Recreation, \\ Sports University of Tirana \\ Corresponding Author \\ Blerina Aliaj \\ Ext. Lecturer, Faculty of Education, \\ Aleksandër Moisiu University \\ Afrim Bilali \\ Faculty of Physical Activity and Recreation, \\ Sports University of Tirana \\ Kliton Muca \\ Albanian National Olympic Committee
}

\section{Doi: 10.2478/jesr-2019-0046}

\begin{abstract}
Sleep is one of the most important biological needs for us humans. Sleep hours vary by age and lack of sleep affects daily functioning of children and adults. The purpose of this study is to determine the hours of waking and sleeping of children and teenagers during the days they go to school in the Tirana. We will determine if there are gender differences. We will determine if the age of the children affects the hours of sleep. This study was conducted in Tirana. The main conclusions of the study are that the largest percentage of Albanian children and teenagers wake up before 8:00 am and sleep after 22:00 darkness. There is no statistically significant difference between girls and boys in their waking and sleeping hours. Teenagers sleep later than children and wake up later than they do.
\end{abstract}

Keywords: sleeping, children, waking hours, teenagers

\section{Introduction}

Sleep is a universal biological feature in all species, and represents a global state of immobility with greatly reduced responsiveness to environmental stimuli. When prevented from sleeping, the body tries to recover the lost sleep time (Brand, Kirov, 2011). Basic human need that it is, restful sleep continues to be an important component of children's overall health and well-being throughout middle childhood and beyond. Well rested children are better able to focus attention and learn during classes or extracurricular activities. In addition, they are more likely to be in a better mood than are poorly rested peers, and more likely to follow rules at home and school. By this age, most children will be able to get all of their necessary sleep in a single overnight session, enabling them to attend school and other after-school activities without need for a nap. However, each child will 
have unique needs. Some children may need more or less sleep to function at their best (Morelli , Dombeck, 2019). The school-age children need 10-11 hours sleep and teenagers need 9-10 hours sleep (RCP, 2019).

But not all children and teens sleep enough, many of them have trouble sleeping. The causes of childhood sleep problems are varied, ranging from primarily medical, medication-related; associated with primary sleep disorders, such as obstructive sleep apnea to the behavioral, related to poor sleep hygiene or inappropriate sleep-onset associations and often represent a combination of these factors. Sleep problems in children must be viewed in the context of the normal, but nevertheless profound, physical, cognitive, neurobehavioral, and emotional developmental changes that occur throughout childhood (Owens, 2005)

A large amount of empirical evidence shows that alterations in sleep quantity or quality do impact on cognitive, affective and, more generally, psychological functions. Therefore, an understanding of a patient's health includes consideration of the state of the patient asleep as well as awake (Cortese, Ivanenko, Ramtekkar, Angriman, 2014). Healthy sleep patterns in childhood and adolescence are associated with lower obesity risk, better psychological well-being, improved cognitive functioning, and lower risk-taking behaviors Sleep among children and teenagers should be a priority in family, school, and clinical contexts, as well as in future basic, observational, and translational research ( LeBourgeois, Hale, Chang, Akacem, Montgomery-Downs, Buxton, 2017).

Several studies have explored the association between sleep problems and combined anxiety and depression. This latter phenotype has been found to be associated with various aspects of disturbed sleep in non-clinical samples. For example, nightmares have been associated with emotional difficulties, while trouble sleeping was associated with parent-reported anxiety/depression in children at age 6 years and again at age (Willis, Gregory, 2015)

How many hours of sleep do Albanian children and teenagers get? At what time do they sleep and at what time do they wake up? Does their age affect their sleeping hours? Is there a difference between boys and girls in this regard? The study of Jarani et al (2016) show that the prevalence of overweight is $10.9 \%$ and obesity $5.7 \%$ among children in Albania. While among Albanian population of children in Balkan the prevalence of overweight and obesity is $21 \%$ (Jarani et al., 2018).

The purpose of this study is to provide a comprehensive overview of the waking and sleeping hours of children and teenagers in Albania making a comparison between the age groups studied. This study will also compare boys and girls between them, determining whether there is a difference in the hours of sleep that they do.

\section{Methodology}

\subsection{Sample}

In this study ( $n=698$ ) children and teenagers participated in the city of Tirana. Questions at what time they woke up were answered $(n=688)$ by children and teenagers and 10 questionnaires turned out to be invalid. Questions at what time did children and teenagers wake up in the morning ( $n=684$ ) were answered by them and 14 questionnaires turned out to be invalid. In this study, $(n=$ 330) questionnaires completed by boys resulted valid and $(n=358)$ questionnaires completed by girls also were valid. Whereas for the school-day sleep schedule the number of boys answered in the study is $(n=327)$ and the number of girls is $(n=357)$.

Children and teenagers were also divided on the basis of their classes. These children and teenagers participated in their waking hours depending on the classes taken in the study. In the first grade $(n=126)$ students participated, $(n=166)$ students from fifth grade, in the ninth grade $(n=$ $192)$ students and in the 12 th grade $(n=204)$ students participated.

Regarding the sleep schedule, they were also divided by their classes. In the first grade ( $n=$ $124)$ students participated, in the fifth grade $(n=166)$ students, in the ninth grade $(n=192)$ students and in the 12th grade $(n=202)$ students participated. 


\subsection{Procedure}

This study was conducted in Tirana. All the school were randomly selected from a pool of 56 school. There were selected 8 schools among the schools in Tirana (the capital city of Albania). Also the classes were randomly selected from the pool of class per each school.

\subsection{Analysis}

The study was conducted in the city of Tirana. The targeted group for the study were explained the purpose of the study, then they completed the questionnaire. After the completed questionnaires were obtained, all data was processed through tables in EXEL. Descriptive statistics and statistical analysis were performed with SPSS software 20 version.

\section{Results}

Referring to Table 1, which shows the wake-up times of the children and teenagers surveyed during the weekdays they go to school, we note that $83.8 \%$ of them wake up before $8: 00 \mathrm{am}, 6.4 \%$ of them wake up between 8:00 am 9:00 am, 5.6\% of them wake up between 9:00 and 10:00 am and $2.7 \%$ of them wake up after 10:00 am.

Table 1: Awakening during School days

\begin{tabular}{|l|l|c|c|}
\hline \multicolumn{2}{|c|}{} & Frequency & Percent \\
\hline \multirow{4}{*}{ Valid } & before 800 & 585 & 83.8 \\
\cline { 2 - 4 } & $8.00-9.00$ & 45 & 6.4 \\
\cline { 2 - 4 } & $900-1000$ & 39 & 5.6 \\
\cline { 2 - 4 } & after 10.00 & 19 & 2.7 \\
\cline { 2 - 4 } & Total & $\mathbf{6 8 8}$ & $\mathbf{9 8 . 6}$ \\
\hline Missing & System & 10 & 1.4 \\
\hline \multicolumn{2}{|l|}{ Total } & $\mathbf{6 9 8}$ & $\mathbf{1 0 0 . 0}$ \\
\hline
\end{tabular}

In Table 2, the data on the sleep time of children and adolescents during the days they go to school are shown. $9.2 \%$ of them sleep before $20.00,22.8 \%$ sleep between $20.00-21.00,30.1 \%$ sleep between $21.00-22.00$ and $36 \%$ sleep after 22.00 .

Table 2: Sleeping during School days

\begin{tabular}{|l|l|c|c|}
\hline \multicolumn{2}{|c|}{} & Frequency & Percent \\
\hline \multirow{4}{*}{ Valid } & before 2000 & 64 & 9.2 \\
\cline { 2 - 4 } & $20.00-21.00$ & 159 & 22.8 \\
\cline { 2 - 4 } & $2100-2200$ & 210 & 30.1 \\
\cline { 2 - 4 } & after 22. 00 & 251 & 36.0 \\
\cline { 2 - 4 } & Total & $\mathbf{6 8 4}$ & $\mathbf{9 8 . 0}$ \\
\hline Missing & System & 14 & 2.0 \\
\hline \multicolumn{2}{|l|}{ Total } & $\mathbf{6 9 8}$ & $\mathbf{1 0 0 . 0}$ \\
\hline
\end{tabular}

Table 3 shows the data for boys and girls as they wake up in the morning during their school days. $83.6 \%$ of boys wake up before $8: 00$ am and $84 \%$ of girls wake up before $8: 00 \mathrm{am} .6 .2 \%$ of boys wake up between $8.00-9.00$ am and $6.6 \%$ girls wake up between $8.00-9.00$ am. $6.2 \%$ of boys wake up between 9:00 am and 10:00 am and 5.2\% of girls wake up between 9:00 am and 10:00 am. $2.2 \%$ of boys wake up after $10: 00$ am and $3.0 \%$ of girls wake up after 10:00 am. 
Table 3: Awakening during School days

\begin{tabular}{|c|c|c|c|c|}
\hline \multicolumn{3}{|c|}{ Gender } & Frequency & Percent \\
\hline \multirow{7}{*}{ Boy } & \multirow{5}{*}{ Valid } & before 800 & 270 & 83.6 \\
\hline & & 8.00-9.00 & 20 & 6.2 \\
\hline & & $900-1000$ & 20 & 6.2 \\
\hline & & after 10.00 & 7 & 2.2 \\
\hline & & Total & 317 & 98.1 \\
\hline & Missing & System & 6 & 1.9 \\
\hline & \multicolumn{2}{|l|}{ Total } & 323 & 100.0 \\
\hline \multirow{7}{*}{ Girl } & \multirow{5}{*}{ Valid } & before 800 & 304 & 84.0 \\
\hline & & $8.00-9.00$ & 24 & 6.6 \\
\hline & & $900-1000$ & 19 & 5.2 \\
\hline & & after 10.00 & 11 & 3.0 \\
\hline & & Total & 358 & 98.9 \\
\hline & Missing & System & 4 & 1.1 \\
\hline & \multicolumn{2}{|l|}{ Total } & 362 & 100.0 \\
\hline
\end{tabular}

Table 4 presents data on boys and girls surveyed about what hours they slept during the days they went to school. $6.8 \%$ of boys and $11.3 \%$ of girls sleep before $20.00 .23 .2 \%$ of boys and $23.2 \%$ of girls sleep between 20.00 and 21.00. $27.2 \%$ of boys and $32 \%$ of girls sleep between 21.00 and $22.00 .39 .9 \%$ of boys and $32 \%$ of girls sleep after 22.00 .

Table 4: Sleeping during School Days

\begin{tabular}{|c|c|c|c|c|}
\hline GENDER & & & Frequensy & Percent \\
\hline \multirow{7}{*}{ Boy } & \multirow{5}{*}{ Valid } & before 2000 & 22 & 6.8 \\
\hline & & $20.00-21.00$ & 75 & 23.2 \\
\hline & & $2100-2200$ & 88 & 27.2 \\
\hline & & after 22.00 & 129 & 39.9 \\
\hline & & Total & 314 & 97.2 \\
\hline & Missing & System & 9 & 2.8 \\
\hline & \multicolumn{2}{|l|}{ Total } & 323 & 100.0 \\
\hline \multirow{7}{*}{ Girl } & \multirow{5}{*}{ Valid } & before 2000 & 41 & 11.3 \\
\hline & & $20.00-21.00$ & 84 & 23.2 \\
\hline & & $2100-2200$ & 116 & 32.0 \\
\hline & & after 22.00 & 116 & 32.0 \\
\hline & & Total & 357 & 98.6 \\
\hline & Missing & System & 5 & 1.4 \\
\hline & \multicolumn{2}{|l|}{ Total } & 362 & 100.0 \\
\hline
\end{tabular}

In Table 5, shows the wake-up time data during school days for the four groups of children surveyed. $89 \%$ of first grade students wake up before $8: 00$ am, also $97 \%$ of 5 th grade students, $83 \%$ of 9 th grade students and $71 \%$ of 12 th grade students wake up at $8: 00 \mathrm{am}$.

$5.5 \%$ of first grade students wake up at $8.00-9.00 \mathrm{am}$, and so does $1.8 \%$ of 5 th grade students, $6.7 \%$ of 9 th grade students, and $10.5 \%$ of 12 th grade students.

Between 9.00 and 10.00 am, $2.4 \%$ of students in 1 st grade, $0 \%$ of 5 th grade students, $6.7 \%$ of 9th grade students and $11 \%$ of 12 th grade students wake up.

$2.4 \%$ of students in 1 st grade, $0.6 \%$ of students in 5 th grade, $2.6 \%$ of 9 th grade students and $4.8 \%$ of 12 th grade students wake up after 10:00am. 
Table 5: Awakening during School days

\begin{tabular}{|c|c|c|c|c|}
\hline \multicolumn{3}{|l|}{ Grade } & Frequency & Percent \\
\hline \multirow{7}{*}{ Grade 1} & \multirow{5}{*}{ Valid } & before 800 & 113 & 89.0 \\
\hline & & $8.00-9.00$ & 7 & 5.5 \\
\hline & & $900-1000$ & 3 & 2.4 \\
\hline & & after 10.00 & 3 & 2.4 \\
\hline & & Total & 126 & 99.2 \\
\hline & Missing & System & 1 & .8 \\
\hline & \multicolumn{2}{|l|}{ Total } & 127 & 100.0 \\
\hline \multirow{7}{*}{ Grade 5} & \multirow{5}{*}{ Valid } & before 800 & 162 & 97.0 \\
\hline & & $8.00-9.00$ & 3 & 1.8 \\
\hline & & $900-1000$ & & \\
\hline & & after 10.00 & 1 & .6 \\
\hline & & Total & 166 & 99.4 \\
\hline & Missing & System & 1 & .6 \\
\hline & \multicolumn{2}{|l|}{ Total } & 167 & 100.0 \\
\hline \multirow{7}{*}{ Grade 9} & \multirow{5}{*}{ Valid } & before 800 & 161 & 83.0 \\
\hline & & $8.00-9.00$ & 13 & 6.7 \\
\hline & & $900-1000$ & 13 & 6.7 \\
\hline & & after 10.00 & 5 & 2.6 \\
\hline & & Total & 192 & 99.0 \\
\hline & Missing & System & 2 & 1.0 \\
\hline & \multicolumn{2}{|l|}{ Total } & 194 & 100.0 \\
\hline \multirow{7}{*}{ Grade 12} & \multirow{5}{*}{ Valid } & before 800 & 149 & 71.0 \\
\hline & & $8.00-9.00$ & 22 & 10.5 \\
\hline & & $900-1000$ & 23 & 11.0 \\
\hline & & after 10.00 & 10 & 4.8 \\
\hline & & Total & 204 & 97.1 \\
\hline & Missing & System & 6 & 2.9 \\
\hline & \multicolumn{2}{|l|}{ Total } & 210 & 100.0 \\
\hline
\end{tabular}

Table 6 shows the sleep schedule data of the children and adolescents who participated in the study divided by class. $29.9 \%$ of 1 st grade students sleep before $8.00 \mathrm{pm}, 9 \%$ of 5 th grade students sleep before $8 \mathrm{pm}, 0 \%$ of 9 th grade children sleep before $8.00 \mathrm{pm}$ and $5.2 \%$ of students 12 th grade sleeps before $8 \mathrm{pm}$. $35.4 \%$ of first grade students, $37.1 \%$ of 5 th grade children, $8.8 \%$ of 9 th grade children and $16.7 \%$ of 12 th grade students sleep between 20.00 and $21.00 .18 .9 \%$ of 9th grade students sleep between 21.00 and 22.00 , same goes for $36.5 \%$ of 5 th grade students, $37.6 \%$ of 9 th grade students and $24.8 \%$ of 12 th grade students. $13.4 \%$ of students in 5 th grade, $16.8 \%$ of 5 th grade students, $52.6 \%$ of 9 th grade students and $49.5 \%$ of 12 th grade students sleep after 22.00 .

Table 6: Sleeping during School Days

\begin{tabular}{|c|c|c|c|c|}
\hline \multicolumn{3}{|l|}{ Grade } & Frequency & Percent \\
\hline \multirow{7}{*}{ Grade 1} & \multirow{5}{*}{ Valid } & before 2000 & 38 & 29.9 \\
\hline & & $20.00-21.00$ & 45 & 35.4 \\
\hline & & $2100-2200$ & 24 & 18.9 \\
\hline & & after 22.00 & 17 & 13.4 \\
\hline & & Total & 124 & 97.6 \\
\hline & Missing & System & 3 & 2.4 \\
\hline & \multicolumn{2}{|l|}{ Total } & 127 & 100.0 \\
\hline \multirow{7}{*}{ Grade 5} & \multirow{5}{*}{ Valid } & before 2000 & 15 & 9.0 \\
\hline & & $20.00-21.00$ & 62 & 37.1 \\
\hline & & $2100-2200$ & 61 & 36.5 \\
\hline & & after 22.00 & 28 & 16.8 \\
\hline & & Total & 166 & 99.4 \\
\hline & Missing & System & 1 & .6 \\
\hline & \multicolumn{2}{|l|}{ Total } & 167 & 100.0 \\
\hline
\end{tabular}




\begin{tabular}{|c|c|c|c|c|}
\hline \multicolumn{3}{|l|}{ Grade } & Frequency & Percent \\
\hline \multirow{7}{*}{ Grade 9} & \multirow{5}{*}{ Valid } & before 2000 & & \\
\hline & & $20.00-21.00$ & 17 & 8.8 \\
\hline & & $2100-2200$ & 73 & 37.6 \\
\hline & & after 22.00 & 102 & 52.6 \\
\hline & & Total & 192 & 99.0 \\
\hline & Missing & System & 2 & 1.0 \\
\hline & \multicolumn{2}{|l|}{ Total } & 194 & 100.0 \\
\hline \multirow{7}{*}{ Grade 12} & \multirow{5}{*}{ Valid } & before 2000 & 11 & 5.2 \\
\hline & & $20.00-21.00$ & 35 & 16.7 \\
\hline & & $2100-2200$ & 52 & 24.8 \\
\hline & & after 22.00 & 104 & 49.5 \\
\hline & & Total & 202 & 96.2 \\
\hline & Missing & System & 8 & 3.8 \\
\hline & \multicolumn{2}{|l|}{ Total } & 210 & 100.0 \\
\hline
\end{tabular}

\section{Discussion}

The main purpose of the study is to determine the awakening and sleeping schedule of Albanian children and teenagers, to determine whether they complete the necessary sleep schedule that they need to function best in their daily lives and to have more productivity and focus on academic results.

The results of the study tell us that most of them wake up before 8:00 in the morning, because they have to go to school and sleep after 22:00 in the evening. Sleep is essential to a healthy life, and it is important to promote healthy sleep habits in early childhood. Children from 6 to 12 years of age should sleep 9 to 12 hours per 24 hours on a regular basis to promote optimal health. Teenagers from 13 to 18 years of age should sleep 8 to 10 hours per 24 hours on a regular basis to promote optimal health (Ciccone, 2016). Referring to the above data it results that Albanian children and adolescents sleep less than the time required in accordance with their age.

Referring to the waking time of boys and girls we can say that the difference between them is statistically insignificant. Even with reference to bedtime, the differences between boys and girls are not significant, although in the lower percentage girls sleep earlier than boys. Other studies have also shown that there is generally no gender difference in sleep patterns. On the other hand, numerous studies based on self-report have noted significant gender differences (Laberge, Petit, Simard, Vitaro, Tremblay, Montplaisir, 2001).

Referring to wake up time, the differences between classes are not statistically significant. Even the sleeping time between groups has no profound differences. However, 9th and 12th grade teens were sleeping in higher percentages after $12 \mathrm{pm}$. Studies of sleep habits of adolescents have shown that they tend to go to bed later and sleep fewer hours than children, thereby exhibiting excessive daytime sleepiness. The reduced sleep quantity is compensated for on weekends when adolescents have no school commitments, allowing them to sleep longer (Natal, Lourenço, Silva, Boscolo, Silva, Tufik, Túlio de Mello, 2009).

Most teenagers are chronically sleep deprived, averaging six to seven hours a night. Part of the blame can be placed on early school start times, which, coupled with many teens' 11 p.m. and midnight bedtimes, resulting in a significant sleep deficit. Sleep debt also has a powerful effect on a teen's ability to learn (Brand, Kirov, 2011).

Changes in sleep behavior are also common in adolescence beginning with the onset of puberty. Physiological changes interact with increases in school demands resulting in less sleep for adolescents. During the school week, adolescents typically sleep between 8 and $9 \mathrm{~h}$ per night. Consistent with younger school age children, teenagers tend to sleep longer during the weekend, averaging between 10 and $11 \mathrm{~h}$ of sleep per week night (Brown, Wilkerson, Boyd, Dewey, Mesa, Bunnell, 2017).

In conclusion we can say that this study provides an overview of the waking and waking hours of a significant sample of children and adolescents but this camping was conducted only in the city of Tirana, which limits the study geographically. 


\section{Conclusions and Recommendations}

The main conclusions of the study are that the largest percentage of Albanian children and teenagers wake up before 8.00 am and sleep after $22.00 \mathrm{pm}$.

There were no statistically significant differences between girls and boys in their waking and sleeping schedules.

Teenagers sleep later than children and wake up later than they are, this is the conclusion of the 3rd study. affect it.

This study serves as a first step, for further in-depth studies on sleep and factors that may

Parents are suggested to be more cautious about their children's sleeping routine, especially for teenagers.

Parents are advised to not place TVs in the bedrooms of children and teenagers.

According to (American Academy of Pediatrics, 2014) the sleep of children is influenced by the time they go to school. It's recommended for relevant instances that school hours are rescheduled to later than 8:00 am.

\section{References}

American Academy of Pediatrics . (2014). School Start Times for Adolescents. Pediatrics, Volume 134 / Issue 3

Brand, Kirov, R. (2011). Sleep and its importance in adolescence and in common adolescent somatic and psychiatric conditions. International Journal of General Medicine, pg 425-442

Brown, W; Wilkerson, A ; Boyd, S; Dewey,D ;Mesa, F : Bunnell, B. (2017). A review of sleep disturbance in children and adolescents with anxiety. Journal of Sleep Research,

Cortese,S; Ivanenko, A; Ramtekkar, U; Angriman, M. (2014). Sleep disorders in children and adolescents a practical guide. Psychiatry and Pediatrics Chapter I.4, pg 2

Ciccone, A. (2016). Official Sleep Recommendations for Children, Adolescents. Wiley

Jarani. J, Spahi. A, Muca. F, Qefalia. D, Tarp. J, Groentved. A, Kasa. A, Shaka. L and Ushtelenca. K (2016). A cross section study on obesity of Albania children living in Balkan area, European Journal of Health \& Science in Sports Volume 3(2) Page 1-6

Jarani. J, Spahi. A, Grontved. A, Muca. F and Tarp. J, (2018), Prevalence of overweight and obesity and anthropometric reference centiles for Albanian children and adolescents living in four Balkan nationstates, Journal of pediatric endocrinology \& metabolism. JPEM 31(11)

Laberge, L; Petit, D; Simard, C; Vitaro, F; Tremblay, R; Montplaisir, J. (2001). Development of sleep patterns in early adolescence. J. Sleep Res. 10, 59-67

LeBourgeois,M ; Hale,L; Chang,A; Akacem, L; Montgomery-Downs,H; Buxton, O. (2017). Digital Media and Sleep in Childhood and Adolescence. Pediatrics, 92-96

Morelli , A; Dombeck, M (2019). Sleep. RISAS

Natal , C; Lourenço, T; Silva, L; Boscolo, R; Silva,A; Tufik, S; Túlio de Mello, M. (2009).Gender differences in the sleep habits of $11-13$ year olds. Brazilian Journal of Psychiatry, vol.31 no.4

Owens,J. (2005.)Insomnia in Children and Adolescents. Journal of Clinical Sleep Medicine, Vol. 1, No. 4, pg 454

Royal Collage of Psychiatrists. (2019). Sleep problems for childhood and adolescence: for parents and carers. RCPsych

Willis, TA and Gregory, AM (2015) Anxiety disorders and sleep in children and adolescents. Sleep Medicine Clinics, 10 (2). 125 - 131. 